Article

\title{
The Influence of Water on the Heat Loss of Hot Mix Asphalt
}

\author{
Paweł Mieczkowski and Bartosz Budziński *(D) \\ Department of Civil Engineering, West Pomeranian University of Technology Szczecin, 70-310 Szczecin, Poland; \\ Pawel.Mieczkowski@zut.edu.pl \\ * Correspondence: bbudzinski@zut.edu.pl
}

Received: 18 March 2019; Accepted: 24 April 2019; Published: 27 April 2019

\begin{abstract}
Compaction of hot mix asphalt (HMA) is a process of altering the internal structure of the material and, as a consequence, also its performance characteristics. The process should ensure the adequate viscosity of binder, a property depending on the temperature and the material-specific property (hardness) of the binder (in the case of HMA). One of the external factors that can affect the process of compaction is the presence of water quickly decreasing the HMA temperature. This paper presents a theoretical model for determining the HMA temperature variation under the effect of water. One of the model parameters is the heat transfer coefficient $\alpha$ for the outward flow of heat. Its value varies strongly in the interfacial zones of the HMA layer (i.e., near the top and bottom surfaces) due to the effect of external factors. The paper presents the attempt to estimate the average value for the whole paving process depending on the precipitation rate (amount of water involved in the process). The temperatures obtained from the model were verified experimentally on laboratory specimens cooled with water. The temperature was measured on the surface and across the specimen section. The drop of temperature of HMA was almost instantaneous on the surface-due to the thermal processes involving water (boiling and evaporation)—and much slower across the layer thickness.
\end{abstract}

Keywords: heat exchange; heat transfer coefficient; thermal conductivity; free (natural) convection; forced convection; hot mix asphalt (HMA)

\section{Introduction}

The main parameter describing the internal structure of hot mix asphalt is its bulk density and corresponding voids. It is determined during compaction. The effectiveness of this process depends on the compaction effort, time and the temperature of the mix being compacted [1-6]. The compaction effort and time can be relatively easily controlled by adjusting the number roller passes on the same path during a given time period. Conversely, it is most difficult to control the temperature during the process, especially when weather conditions vary $[5,7,8]$.

Quick and considerable drops of temperature are a big challenge in the HMA laying process specifically in cases like thin noise reducing asphalt layers (TAL) or ultra-thin asphalt surfacing. This concerns in particular the interfacial zones (top and bottom surfaces) exposed to the direct action of external factors. The viscosity of the binder increases rapidly at these locations in the profile. With a higher than desired viscosity it is more difficult to obtain adequate compaction. Insufficient compaction increases the content of voids which can decrease the HMA's resistance to external factors.

One of the factors increasing the rate of heat absorption from the interfacial zones of HMA is water. Water can appear both on the top surface (coming from precipitation or wetting of the steel wheels of rollers) and on the underside of the layer, especially when placed on a damp base of unbound material (for example compacted aggregate). The amount of heat lost due to the effect of water depends on the initial HMA temperature, on the amount of water and on the intensity of phase change processes 
(boiling, evaporation), which are activated by the input of energy from HMA. Additionally relevant is the water/ HMA contact location (bottom or top surface) since it defines the type of convection and water vapor flow conditions.

Coming in contact with the top surface of the HMA layer water initiates the following processes:

- Intensive boiling and evaporation in the first seconds (until the surface temperature has dropped below $\left.100^{\circ} \mathrm{C}\right)$,

- quite intensive evaporation of water (when present in small amounts) over a period of few minutes (depending on the humidity and temperature of the ambient air and also on the wind speed),

- film formation (impeding evaporation) and retarded transfer of heat by conduction from HMA to the ambient air (through the thin film of water),

- next the heat flux stabilises (heat propagates from the inside to the surface and the surface temperature is virtually constant).

When HMA comes in contact with a damp substrate the following processes are initiated:

- Intensive boiling and evaporation (in the first seconds) until the surface has cooled off (to below $100^{\circ} \mathrm{C}$;

- Infiltration of water vapor into the HMA layer (resulting in excessive cooling and increase of the binder viscosity);

- Slow heat propagation from the inside to the bottom of the layer without boiling and evaporation at the lower interface (bottom surface).

The consequences of quick cooling are also different between the top and bottom surfaces:

- The top surface can get more susceptible to the weather and ambient factors (water, UV radiation, temperature) due to a higher voids content;

- In the bottom zone a higher content of voids reduces the tensile stress resistance of the layer (resulting in premature fatigue distress and low-temperature cracking, etc.) [9-11].

The heat losses related to the presence of water are many times greater than the amounts of heat removed by other external factors (wind, air, substrate, elements of compacting equipment) with the greatest portion of energy consumed in the boiling process (in any form). The parameter describing the material's ability to absorb heat is the heat transfer coefficient $\alpha$ (Figure 1). Its value can vary over a very wide range. The relevant factors are the type of water movement (free or forced convection), level of turbulence (laminar or turbulent flow), position of the heat exchange surface (top or bottom surface of the layer) and, last but foremost-the characteristics of the boiling and evaporation processes.

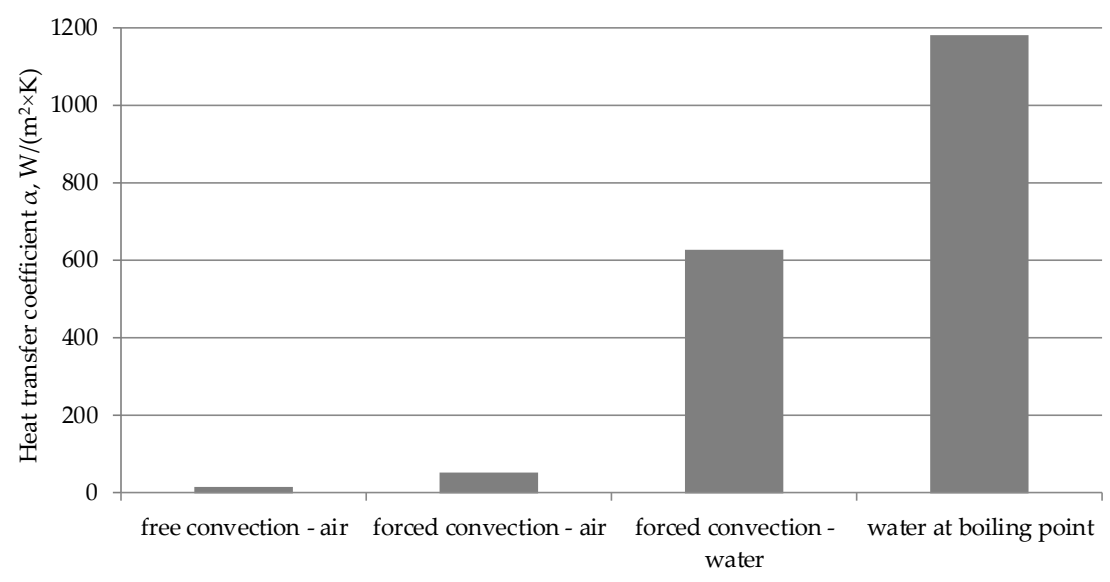

Figure 1. Example values of $\alpha$ for air (for free and forced convection) and for water (for forced convection and laminar flow and for boiling). 
The article describes the influence of small water amounts on the rate of cooling down of the HMA layer. The theoretical drop of the temperature in the layer of HMA was determined based on the Fourier differentiation (Section 2). The model parameters and the method of their determination is presented in Section 3. The focus of the study was put on the coefficient of the heat transfer to the water, which was determined from a simplified formula. The study of temperature drops in the HMA layer was presented in Section 4. Acquired measurements allowed to revise the formula for determination of the $\alpha$ coefficient taking into account the physical changes and small water amount. The theoretical values were compared to experiment results of HMA samples cooled down with $3 \mathrm{~L} / \mathrm{m}^{2} / \mathrm{h}$ and $6 \mathrm{~L} / \mathrm{m}^{2} / \mathrm{h}$ of water.

\section{Heat Flow in the HMA Layer-Theoretical Model}

The heat flow in the HMA layer is caused by transient (unsteady state) heat conduction. The rate of heat propagation depends on the thermal conductivity $\lambda$ of HMA and the heat transfer coefficient $\alpha$ which is a measure of the ability of the surrounding medium to absorb heat (Figure 2).

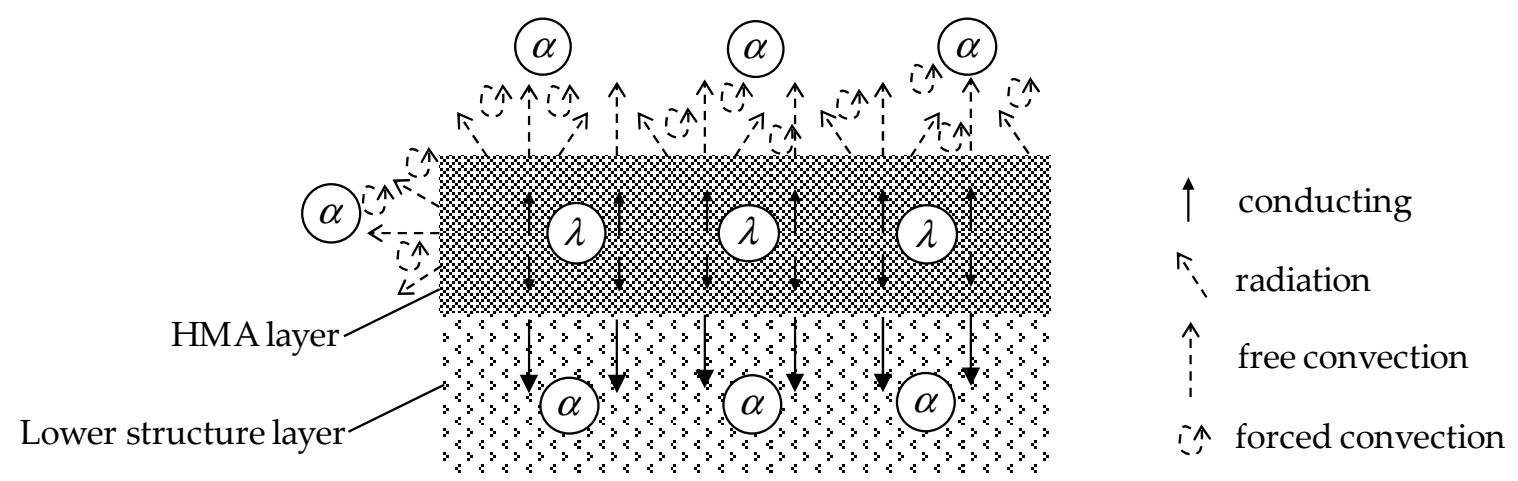

Figure 2. Heat flow in the Hot Mix Asphalt (HMA) layer and heat transfer during the cooling process.

The process is governed by the Fourier law in the differential form expressed as a product of two functions: Time and space (1) [12]:

$$
T_{(x)}=T_{\text {med }}+\left[\left(\sum_{n=1}^{n=\infty} e^{-\delta_{n}^{2} F o} \frac{2 \sin \delta_{n}}{\delta_{n}+\sin \delta_{n} \cos \delta_{n}} \cos \delta_{n} \frac{x}{s_{m}}\right) \times\left(T_{\text {in }}-T_{m e d}\right)\right]
$$

where: $T_{(x)}$-temperature inside the layer at time $\tau$ and at a distance $x$ from the layer middle plane of the layer $[\mathrm{K}], T_{\text {in }}$-initial temperature of the layer at time $\tau=0[\mathrm{~K}], T_{\text {med }}$-temperature of the medium surrounding the body $[\mathrm{K}], s_{m}$-perpendicular distance between the layer surface and middle plane $(\mathrm{m})$, $x$-distance of the point in consideration from the middle plane of the layer [m], Fo-Fourier number.

The Fourier number is determined with the (2) formula [12]:

$$
F o=\frac{\lambda \times \tau}{\rho_{b} \times c \times s_{m}^{2}}
$$

where $\lambda$-thermal conductivity coefficient of the HMA layer $[\mathrm{W} /(\mathrm{m} \cdot \mathrm{K})]$, $\tau$-time from the beginning of the heat transfer process $[\mathrm{s}], \rho_{b}$ - bulk density of the HMA layer $\left[\mathrm{kg} / \mathrm{m}^{3}\right], c$-specific heat of HMA [J/(kg.K)].

The values of $\delta_{n}$ correspond to the points of intersection of the following two functions: $y_{1}=\operatorname{ctg} \delta$ and $y_{2}=\delta / B i$. The Biot number is determined from the formula (3) [12-16]:

$$
B i=\frac{\alpha \times s_{m}}{\lambda}
$$

where: $\mathrm{Bi}-$ Biot number, $\alpha$-heat transfer coefficient of the surrounding medium $\left[\mathrm{W} /\left(\mathrm{m}^{2} \cdot \mathrm{K}\right)\right]$. 
It is quite easy to define most parameters of the theoretical model described by equation (1). Two of them, however, require more attention, namely: Thermal conductivity $\lambda$ of HMA and the heat transfer coefficient $\alpha$ of the surrounding medium (3).

HMA does not classify as a good heat conductor. Based on the author's own studies their value of $\lambda$ ranges from ca. 0.50 to $1.30 \mathrm{~W} /(\mathrm{m} \cdot \mathrm{K})$ [17]. The exact value depends on a number of factors, including proportions of ingredients (binder, aggregate), rock characteristics (density and porosity), content and type of voids: Connected (open) or isolated (closed). Relatively small values of $\lambda$ indicate that in the case of the high amount of heat transfer to the surrounding media temperature stratification will occur in the layer with the high cooling rate on the surfaces and small temperature drops inside the layer. This is caused by a much slower propagation of heat from the inside to the surfaces of the layer in relation to its release rate to the surrounding media (air, underlying courses of pavement, etc.).

\section{Heat Transfer to the Environment by Combined Convection and Conduction}

\subsection{Heat Transfer to Air}

At the time of placement of HMA heat is released primarily by the top and bottom surfaces of the HMA layer (Figure 2). The release of heat through the sides is limited to the verge strip within $10-20 \mathrm{~cm}$ from the layer edge [7]. The heat released by the top surface is absorbed mainly by fluid and gaseous media (air and water used in the process) and only in a small amount by solid bodies (steel wheels). The bottom surface releases heat to the substrate (of varying moisture content).

The surrounding air receives heat through convection (in combination with conduction in the thin interfacial zone) and by radiation. The amount of this heat transfer is defined by the overall heat transfer coefficient $\alpha(4)[12-16,18,19]$ :

$$
\alpha=\alpha_{\text {free }}+\alpha_{\text {for }}+\alpha_{\text {rad }}
$$

where: $\alpha_{\text {free }}$-natural convection component $\left[\mathrm{W} /\left(\mathrm{m}^{2} \cdot \mathrm{K}\right)\right], \alpha_{\text {for }}$-forced convection component, $\alpha_{\text {rad }}$-radiative component.

For more details on the methods of determining the components of the overall heat transfer coefficient refer to the literature $[12,15,16,20,21]$. Examples of the $\alpha$ coefficient of heat transfer to air depending on the characteristic dimension $(d)$ and wind velocity are shown in Figures 3-5.

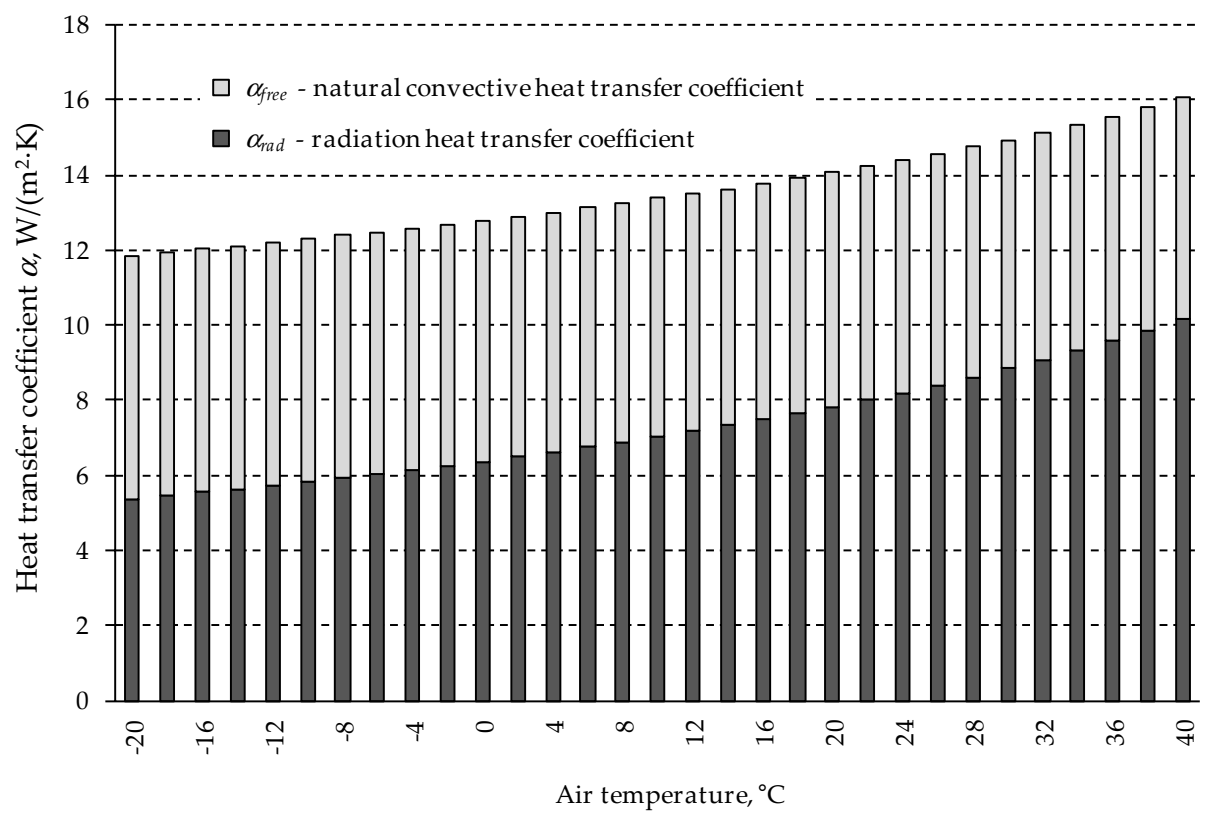

Figure 3. Relationship between the temperature (without the wind and heat transfer coefficient to air $\alpha$ ). 


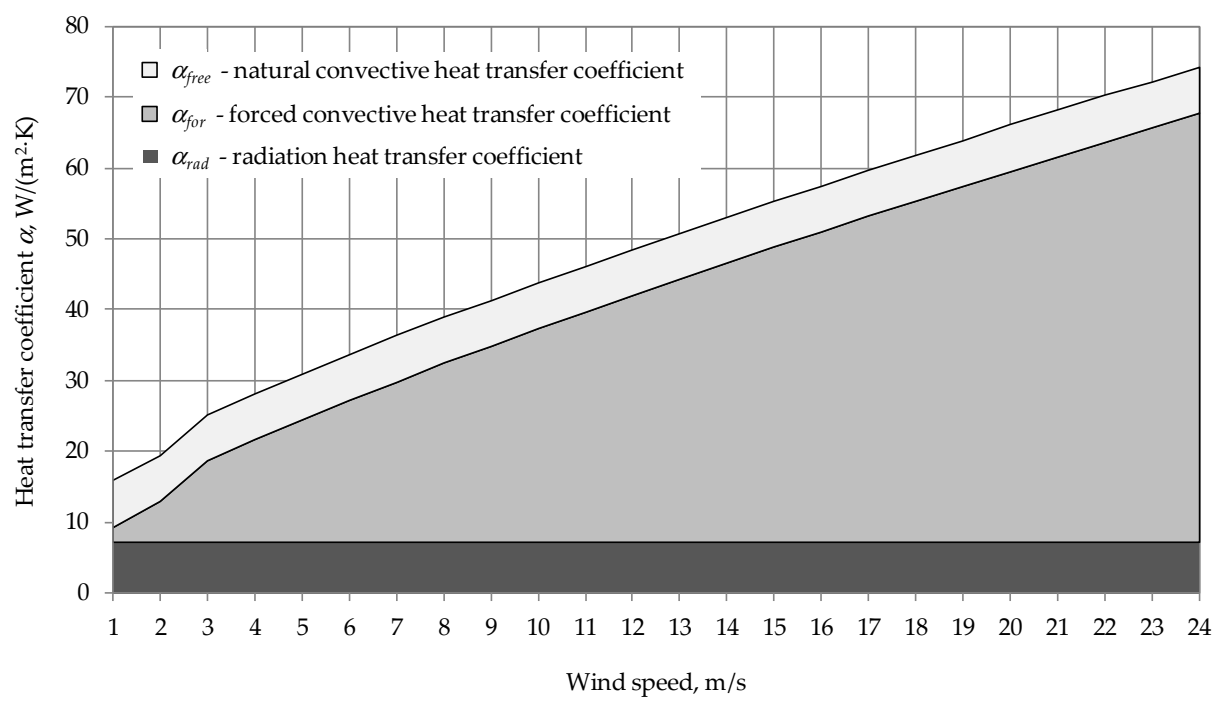

Figure 4. Relationship between the heat transfer coefficient to air $\alpha$ and wind velocity for a $d=3.5 \mathrm{~m}$ hot mix asphalt (HMA) layer.

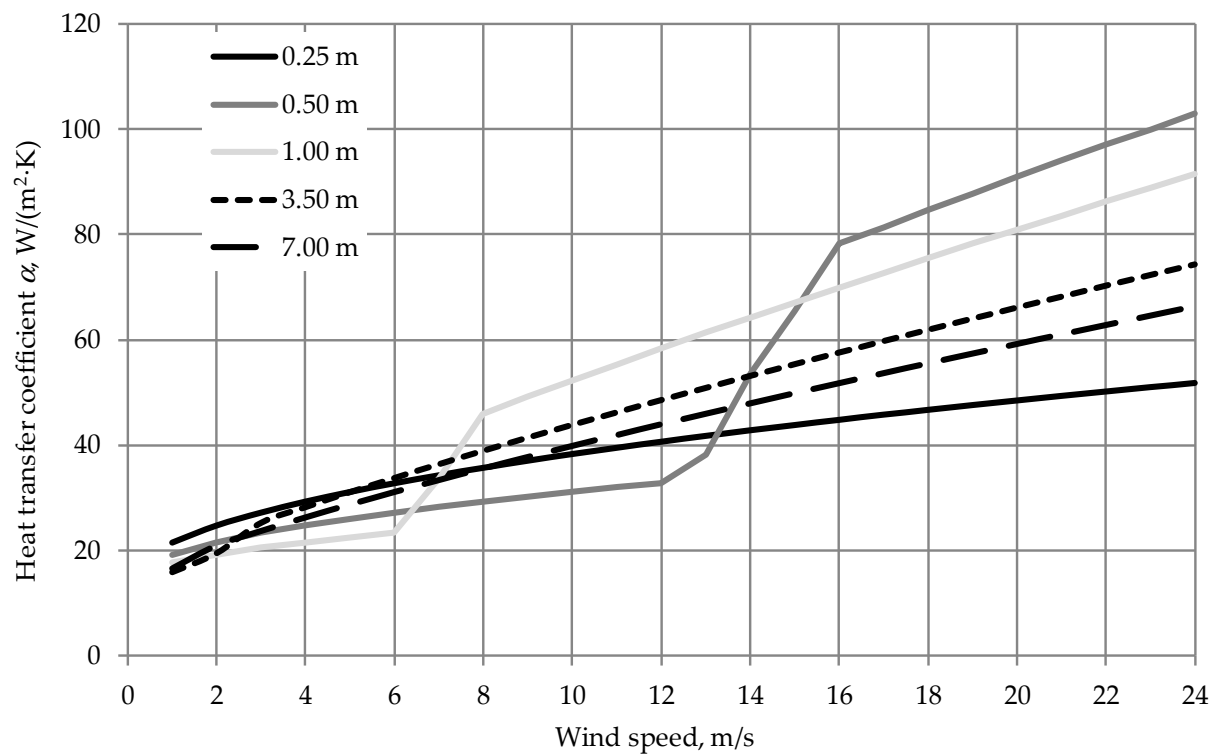

Figure 5. Relationship between the heat transfer coefficient to air $\alpha$ and wind velocity (HMA layer width $d=0.25 \mathrm{~m}-7.0 \mathrm{~m})$.

\subsection{Heat Transfer to Solid Bodies}

Unless there are any gaps in between, the transfer of heat between HMA and bodies (underlying layers of pavement, surfaces of compacting machines) is by conduction. The efficiency of this process is described by the equivalent heat transfer coefficient, calculated with equation (5) $[12-14,18,19]$. This form of heat propagation should not cause rapid temperature changes across the depth of the HMA layer.

$$
\alpha_{z}=\frac{\lambda_{z}}{h_{z}}
$$

where: $\lambda_{z}$-thermal conductivity of a material classified in the solids group $[\mathrm{W} /(\mathrm{m} \mathrm{K})], h_{z}$ 一thickness of the layer absorbing heat [m].

In the case of underlying layers (lower asphalt layers, unbound aggregate layers, etc.) their low thermal conductivity is the decisive factor in this respect. For the asphalt layers the value of $\alpha_{\mathrm{z}}$ varies in the range of $3-26 \mathrm{~W} /\left(\mathrm{m}^{2} \cdot \mathrm{K}\right)$. In terms of thermal performance the unbound materials with a typically 
greater voids content (in the order of $15-25 \%$ ) classify in the group of loose-fill materials $[12,15,16]$ with the value of $\alpha_{\mathrm{z}}$ in the range of ca. $1.5-4.5 \mathrm{~W} /\left(\mathrm{m}^{2} \cdot \mathrm{K}\right)$.

The equivalent heat transfer coefficient $\alpha_{\mathrm{z}}$ of the steel wheel of rollers is in the range of ca. 2100 to $5300 \mathrm{~W} /\left(\mathrm{m}^{2} \cdot \mathrm{K}\right)$. The factors responsible for that are the high thermal conductivity of steel (47 to $95 \mathrm{~W} /(\mathrm{m} \cdot \mathrm{K})$ - depending on the density of steel and content of carbon) and small thickness of the steel wheel shell (ca. 18-23 mm). The values of $\alpha_{\mathrm{z}}$ being so high, the amount of heat absorbed by the steel wheel is small due to a very short duration of contact with the compacted surface ( $3-5 \mathrm{~s})$. For pneumatic tyre rollers the value of $\alpha_{\mathrm{z}}$ is in the range of $4-15 \mathrm{~W} /\left(\mathrm{m}^{2} \cdot \mathrm{K}\right)$ due to the low thermal conductivity of rubber $(0.13-0.3 \mathrm{~W} /(\mathrm{m} \cdot \mathrm{K}))$, the exact value depending on the rubber composition and variety.

\subsection{Heat Transfer to Water}

The reported drops of temperature through the thickness of the HMA layer as a function of time $[20,22,23]$ are based on constant values of $\alpha$ and $\alpha_{z}$. The calculations assume the transfer of heat from the bottom surface to a dry substrate and from the top surface to the air and the compacting roller components (steel or rubber as appropriate). The temperature of air, wind speed and the number of passes and working speed of the compacting roller are taken into account. However, the effect of water is ignored. Under these theoretical assumptions heat should be released primarily through the top surface of the layer (through convection).

Apart from conduction, radiation and convection in field conditions there are other phenomena involved in the heat transfer process, which increase the absorption of heat from HMA. They are caused by the presence of water and the physical transformations in which it takes part. The removal of heat related to the presence of water can concern both the bottom and top surfaces of the placed HMA layer and its intensity varies over time.

On the underside of the layer water has only a transient effect, even at a high moisture content of the substrate. This is related to a very high amount of heat removed from the interfacial zone (on the bottom surface) that is in direct contact with water. The removed heat is used to heat up the small quantity of water and turn it to vapor. Water vapor moves up making its way through the voids of the not yet compacted HMA. On the way up the water vapor removes heat from the upper strata thus intensifying the cooling process. The amounts of heat removed at the layer underside are at this point much smaller due to the drop of the HMA temperature (to below $100^{\circ} \mathrm{C}$ ). Boiling and vaporization do not take place and heat is transferred through conduction and free convection (this allowed by big voids). In addition, increasing the voids content water can affect the bond between the layers.

Water coming from precipitation or wetting of steel wheels causes instantaneous drops of temperature in the upper part of the interfacial zone of the HMA layer. This is caused by the removal of heat that is used for heating up water and initiating the boiling and vaporization process. The intensity of the boiling and vaporization processes depends on the difference of the temperature of the hot surface $T_{S}$ (surface of the HMA layer) and saturation temperature $T_{n}$ (which depends on the pressure).

With moderate heating intensity (heat flux density) heat is transferred by free convection even when the temperature of the heat exchange surface is slightly higher than the saturation temperature. $\left(T_{S}-T_{n}=0-3 \mathrm{~K}\right.$, Figure 6). Convection currents cause the fluid to move up and vapor is formed only on the free surface of the fluid in the process of surface evaporation. The free convection heat transfer coefficient for fluids is proportional to $\left(T_{S}-T_{n}\right)^{0.25}$ and the flux density of the absorbed heat is proportional to $\left(T_{S}-T_{n}\right)^{1.25}[10,15,17,18]$. An increase of the heat flux density (for greater temperature differences on the heat exchange surface: $T_{S}-T_{n}=3-30 \mathrm{~K}$ ) increases the amount of steam bubbles which grow in diameter to come apart and move towards the surface of the fluid (nucleate boiling). This results in vigorous mixing of the fluid, increasing the heat exchange intensity. In the nucleate boiling process the heat transfer coefficient is roughly proportional to $\left(T_{S}-T_{n}\right)^{2}$ and the absorbed heat flux density is roughly proportional to $\left(T_{S}-T_{n}\right)^{3}[10,15,18]$.

With the temperature difference in excess of $30 \mathrm{~K}$ more bubble formation centers develop, which tend to combine, forming larger, irregular bubbles separating the heating surface from the fluid, thus 
impeding the heat exchange process. The changes of the heat transfer coefficient and heat flux density are presented in Figure 6.

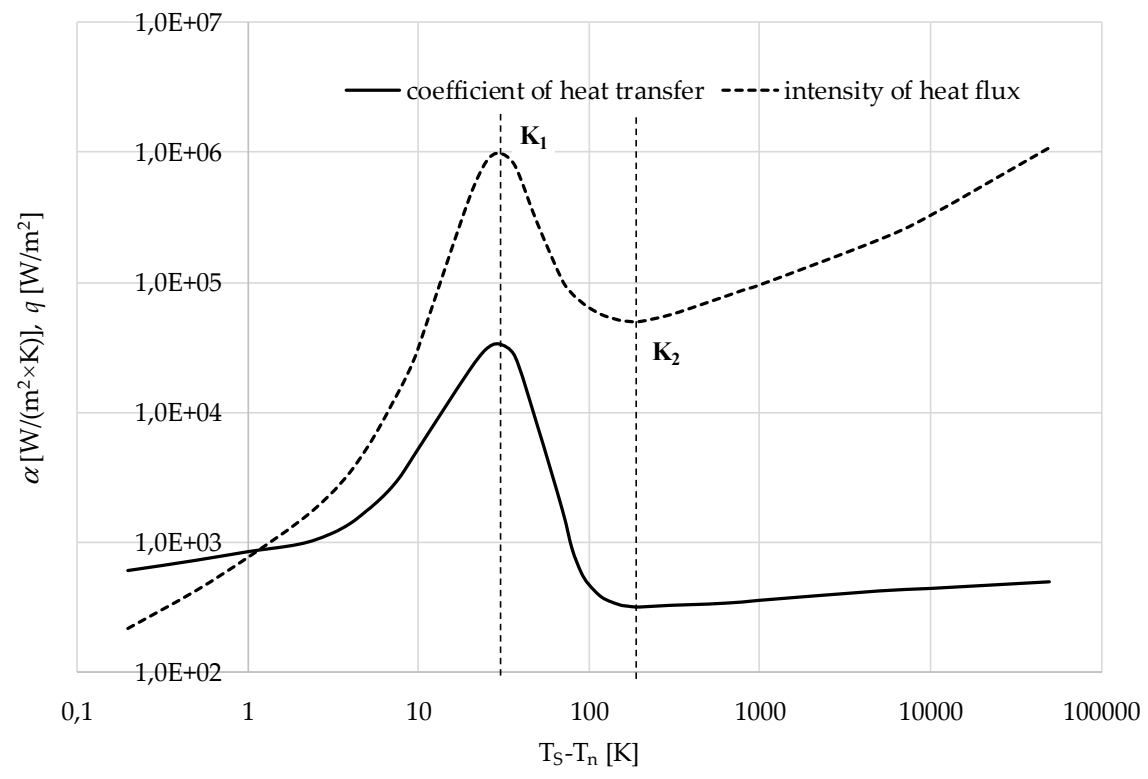

Figure 6. Relationships between the heat flux density $\mathrm{q}$ and the heat transfer coefficient $\alpha$ and the difference between the hot surface/saturation temperatures $\left(T_{S}-T_{n}\right)[19,24,25]$. Legend: $K_{1}-c r i t i c a l$ heat flux, $\mathrm{K}_{2}$-Leidenfrost point.

Regardless of the intensity of the heat transfer process the physical changes in water require vast amounts of energy. Boiling is the first-order phase transition and, in constant pressure conditions, a prior absorption of vaporization heat by water is necessary for it to take place. Over $85 \%$ of this heat is used in the phase transition process (this due to a very high vaporization heat of water which is $2.26 \mathrm{MJ} / \mathrm{kg}$ ) and ca. $15 \%$ is needed to bring water from the initial to the boiling temperature (Figure 7). Only a small portion of this energy (ca. $0.1 \%$ ) is used to increase the water vapor temperature. The primary factor determining the energy intensity of the process is the weight of water involved in it. Minimized and controlled use of water can have a decisive bearing on the properties of the HMA layer. The influence of the water temperature on the amount of the energy required for the vaporization is insignificant.

As a result of water impact, the surface cools down quickly (within a few dozen seconds) to the temperature below $80-100{ }^{\circ} \mathrm{C}$ in 3-6 mm deep zone (depending on the mixture type). When the temperature has dropped near the surface of the HMA layer any new water will form a thin film atop of it. The amount of water acting on the surface will define the further course of the heat transfer processes. When there is only a small amount of water involved, the process starts with equalization of temperatures between water (in the form of thin film) and the HMA surface and then heat is transferred through conduction (in the water film) and free (natural) convection to air. Further on, the gradual evaporation of water will occur in addition to the above-described processes at a rate depending on the degree of water vapor saturation of the ambient air and the surface temperature of the HMA layer. If a large amount of water is involved (heavy rain) heat will be transferred between HMA and water by free or forced convection-depending on the intensity of the heat transfer process and the flow velocity of water. In the case of porous mixtures water can partly penetrate deeper into the HMA layer continuing intensive cooling of the layer material.

The observations during compaction of HMA layers did not reveal any formation of larger bubbles of water vapor on the hot surface or occurrence of pool boiling. The HMA temperature, surface texture and the amount of water are the decisive factors in this respect. Thus we can assume that the difference between the hot surface temperature and the saturation temperature does not exceed $30 \mathrm{~K}$ and boiling 
does not occur. This is primarily due to quick cooling down of the HMA surface (heat source) bringing the heat exchange temperature range to $T_{S}-T_{n}=0-3 \mathrm{~K}$.

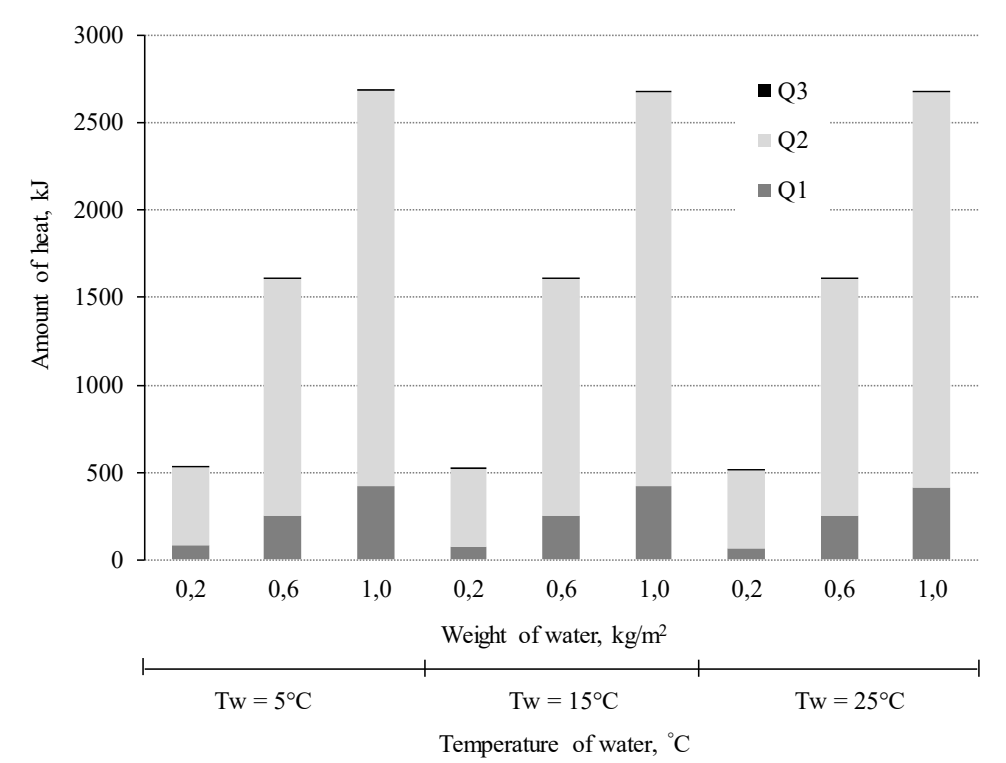

Figure 7. Amount of heat needed to vaporize water having initial temperatures of 5,15 and $25^{\circ} \mathrm{C}$ and to heat up water vapor to $120^{\circ} \mathrm{C}$. Legend: Q1-amount of heat used to heat up water from its initial temperature to $100^{\circ} \mathrm{C}, \mathrm{Q} 2$ - amount of heat used in the vaporization process, Q3-amount of heat used to rise the water steam temperature to $120^{\circ} \mathrm{C}$.

Assuming the constant thickness of water pool the value of natural convection heat transfer coefficient can be determined with equation (6) for laminar flow $\left(\alpha_{\text {free }}^{l}\right)$ and equation (7) for turbulent flow $\left(\propto_{\text {free }}^{t}\right)$ [12]:

$$
\begin{gathered}
\alpha_{\text {free }}^{l}=A \cdot\left(\frac{\Delta T}{d}\right)^{\frac{1}{4}} \\
\propto_{\text {free }}^{t}=\frac{0.14}{0.59} \cdot A \cdot(\Delta T)^{\frac{1}{3}}
\end{gathered}
$$

where: $A$-constant defining the type of water flow (Table 1 ).

\begin{tabular}{|c|c|c|c|c|c|c|c|c|}
\hline \multirow{2}{*}{$\begin{array}{c}\text { Parameter } \\
\text { Temperature, }{ }^{\circ} \mathrm{C}\end{array}$} & \multicolumn{4}{|c|}{$\begin{array}{c}\text { Laminar Flow } \\
\left(\mathrm{Gr} \cdot \operatorname{Pr}=5 \cdot 10^{2} \div 2 \cdot 10^{7}\right)\end{array}$} & \multicolumn{4}{|c|}{$\begin{array}{l}\text { Turbulent Flow } \\
\left(\mathrm{Gr} \cdot \operatorname{Pr}>2 \cdot 10^{7}\right)\end{array}$} \\
\hline & 40 & 60 & 80 & 100 & 40 & 60 & 80 & 100 \\
\hline Values of A & 128 & 153 & 176 & 195 & 250 & 312 & 366 & 414 \\
\hline
\end{tabular}

Table 1. Values of A constant for water excluding the effect of radiation [12,19].

The values of the A constant determined for the water temperature is the average of the initial water temperature and the initial temperature of the HMA layer.

The flow type is determined by the value of the product of the Grashof number (Gr) and Prandtl number $(\operatorname{Pr})[12,15,16,24]$ :

$$
\begin{gathered}
\operatorname{Pr}=\frac{c_{p} \eta_{p}}{\lambda_{p}} \\
\mathrm{Gr}=\frac{g \beta \Delta T d^{3} \gamma_{p}^{2}}{\eta_{p}^{2}}
\end{gathered}
$$

where: $c_{p}$-specific heat of fluid (water) at a constant pressure $[\mathrm{J} / \mathrm{kg} \cdot \mathrm{K}], \eta_{p}$-dynamic viscosity coefficient of water at a constant pressure $\left[\mathrm{N} \cdot \mathrm{s} / \mathrm{m}^{2}\right], \lambda_{p}$-thermal conductivity of water at a constant pressure 
$[\mathrm{W} /(\mathrm{m} \cdot \mathrm{K})], \mathrm{g}$-acceleration of terrestrial gravity force $\left[9.81 \mathrm{~m} / \mathrm{s}^{2}\right], \beta$-volumetric coefficient of thermal expansion of fluid (water), calculated as $1 / T_{m}[1 / \mathrm{K}], \Delta T-\mathrm{HMA}$ surface $\left(T_{m}\right) /$ water temperature difference $[\mathrm{K}], d$-characteristic dimension of cooled HMA layer (width) $[\mathrm{m}], \gamma_{p}$ —water density $\left[\mathrm{kg} / \mathrm{m}^{3}\right]$,

The properties of water are determined for the average temperature $T_{m}$ are derived from (10):

$$
T_{m}=\frac{T_{i n}+T_{m e d}}{2}
$$

where: $T_{m}$-the average of the initial HMA surface temperature and the initial water temperature $[\mathrm{K}]$. Equations (6) and (7) were derived on the basis of experimental results with the value of $A$ constant determined for a water film with a constant thickness and temperature. Actually, during placement of HMA both the thickness and temperature of the water film vary both for water present in the damp substrate (the bottom surface of HMA layer) and for water used for wetting steel wheels of compacting rollers (the top surface of HMA layer). Other factors affecting the value of $A$ are the physical transformations of water during the placement of HMA (boiling and evaporation) and heat release by radiation. These processes significantly affect the heat removal from the hot surface of HMA. In response to these differences it was necessary to adjust the values of $A$, and, as a consequence, also the value of the heat transfer coefficient $\propto_{\text {free }}$.

\section{Laboratory Verification of the Value of $A$ Constant}

Due to the complicated nature of the processes on the surface of the HMA layer cooled down with small amounts of water, the authors assumed that the heat transfer coefficient $\alpha$ derived from the (6) and (7) formulae needs to incorporate the main types of heat transfer. The authors chose convectional heat transfer with air and water and radiation heat transfer. The assumption required the revision of the $A$ parameter (Table 1) which was determined in the study for constant thickness of the water layer with determined (constant) temperature. Therefore, the value of the $\alpha$ will be the sum of heat transfer coefficient to $\left(\alpha_{\text {free }}, \alpha_{\text {rad }}\right)$ air and $\left(\alpha_{\text {free }}\right)$ water.

To determine the values of the A parameter (including mentioned forms of heat transfer) the following steps were taken:

(1) Preparation of seven HMA samples, varying with mix type, application and properties;

(2) Determination of basic physical and thermal properties (density, bulk density, voids, thermal conductivity coefficient $\lambda$, specific heat $c$ ) of the HMA samples;

(3) The tests were conducted to determine the temperature changes after $1 \mathrm{~h}$ in a cross-section of 3 chosen HMA samples (initial assumption: Temperature of water and air $0,5,15$ and $25^{\circ} \mathrm{C}$, amount of water $3 \mathrm{~L} / \mathrm{m}^{2} / \mathrm{h}$ );

(4) Calculation of the theoretical temperature in the HMA samples from the formula (1) for assumed conditions (the value of the heat transfer coefficient $\alpha$ was calculated from (6) and (7) for the $A$ parameter corresponding to the average temperature $\left.T_{m}\right)$;

(5) Determination of average deviations between the measured and theoretical temperatures for the assumed values of $A$ parameters;

(6) Correction of the $A$ parameter values by means of iteration, based on the smallest average deviations between the measured and theoretical temperature for three time periods $(0-5 \mathrm{~min}$; 5-60 $\mathrm{min} ; 0-60 \mathrm{~min})$;

(7) Verification of assumed values of the $A$ parameter (for whole time range of 0-60 $\mathrm{min}$ ) based on the measurements of temperature changes of the other four HMA samples;

(8) Repeating the tests for determination of the temperature changes and determination of the $A$ parameter for HMA samples cooled down with $6 \mathrm{~L} / \mathrm{m}^{2} / \mathrm{h}$ of water;

(9) Determination of the heat transfer coefficient $\alpha$ in regards to the average water temperature $\left(T_{m}\right)$ and layer width $(d)$ for $3 \mathrm{~L} / \mathrm{m}^{2} / \mathrm{h}$ and $6 \mathrm{~L} / \mathrm{m}^{2} / \mathrm{h}$ water amount. 
Seven specimens were used, made of different HMA mixes. Three specimens were used for determining the value of $A$ (based on the smallest average deviations). Two of them were made of asphalt concrete mixes: AC $16 \mathrm{~W}$ (W-for binder course) and AC $8 \mathrm{~S}$ (S-for wearing course) and one of stone mastic asphalt SMA 11. The remaining four specimens were used for verification of the adopted $A$ values. Three of them were made of asphalt concrete mixes: AC $22 \mathrm{P}$ ( $\mathrm{P}-$ for base course), AC $11 \mathrm{~W}, \mathrm{AC} 11 \mathrm{~S}$ and one of stone mastic asphalt SMA 8. The thermophysical parameters of HMA samples are shown in Table 2. The specific heat $c$ was determined using the calorimeter, while the thermal conductivity coefficient $\lambda$ was determined using the heat flow meter apparatus at $20^{\circ} \mathrm{C}[12,17]$.

Table 2. Thermophysical parameters of the HMA samples.

\begin{tabular}{cccccc}
\hline \multirow{2}{*}{ Type of HMA } & \multicolumn{5}{c}{ Physical and Thermal Properties of HMA } \\
\cline { 2 - 5 } & $\rho_{\boldsymbol{m} v}\left[\mathrm{~g} / \mathbf{c m}^{3}\right]$ & $\rho_{\boldsymbol{b}}\left[\mathrm{g} / \mathrm{cm}^{\mathbf{3}}\right]$ & $V[\%]$ & $\lambda[\mathbf{W} /(\mathbf{m} \cdot \mathbf{K})]$ & $c[\mathbf{J} / \mathbf{( k g} \cdot \mathbf{K})]$ \\
\hline AC 8 S & 2.705 & 2.644 & 2.26 & 0.938 & 0.815 \\
AC 11 S & 2.715 & 2.606 & 4.01 & 0.857 & 0.817 \\
AC 11 W & 2.757 & 2.609 & 5.37 & 0.870 & 0.816 \\
AC 16 W & 2.775 & 2.601 & 6.27 & 1.151 & 0.818 \\
AC 22 P & 2.795 & 2.608 & 6.69 & 1.057 & 0.821 \\
SMA 8 & 2.669 & 2.601 & 2.55 & 0.723 & 0.819 \\
SMA 11 & 2.681 & 2.581 & 3.73 & 0.684 & 0.822 \\
\hline
\end{tabular}

$\rho_{m v}$ - density of HMA, $\rho_{b}$-bulk density of HMA, $V$-void, $\lambda$-thermal conductivity coefficient of HMA, $c$-specific heat of HMA.

The $A$ values were calculated with the iterative method using the smallest mean deviations $(\Psi)$ between the actual temperature (determined in laboratory) and the theoretical temperature $(\Psi(\mathrm{A}) \rightarrow \mathrm{min})$. The deviations were calculated as follows (11):

$$
\Psi=\frac{\sum \sqrt{\left(T_{\text {theor }}-T_{\text {lab }}\right)^{2}}}{n}
$$

where: $T_{\text {theor }}$-theoretical temperature obtained from the model (1) [ $\left.{ }^{\circ} \mathrm{C}\right], T_{\text {lab }}$-actual temperature measured in the laboratory $\left[{ }^{\circ} \mathrm{C}\right], n$-number of readings taken.

$A$ was the variable in these calculations. The temperature of water was taken as the average of the initial temperature of water and the temperature of the HMA surface.

The actual drops of temperature within the HMA layer as a result of spraying the material with water were determined on specimens compacted in the laboratory (Figure 8). The HMA sample thickness was between 42 to $47 \mathrm{~mm}$. The specimens were insulated on the bottom and side surfaces. As a result, heat was released solely through the top surface which was additionally cooled with water. The measurements were carried out with a pyrometer-for surface temperature and with the use of thermocouples-for the inside temperature of the layer. The thermocouples were placed at an appropriate depth in pre-drilled holes filled with hot-poured mix (bitumen/ fine grain natural crushed aggregate).

The measurement of the temperature on the surface of the sample was taken using pyrometer from the distance of 20-30 cm. Standard optics were used, resulting in a measurement area with the diameter of approximately $20 \mathrm{~mm}$ (Figure 9). This allowed to precisely place the measured areas on the HMA sample (using laser sight). The measuring equipment had an accuracy of measurement of $\pm 0.75 \%$ with test repeatability of $\pm 0.50 \%$.

The measurement of internal temperatures was conducted using thermoelectrical thermometers. Those special devices measure the changes in the temperature by measuring the changes in the thermoelectric force of the thermocouple. The temperature measurements were acquired thanks to the additional setup (by external clamp) of electric measuring equipment: Measuring point change-over switch and digital indicator. Thermocouples and compensating $\mathrm{K}$ type nickel-alloy nickel-chromium 
(Ni-NiCr) thermocouples, class I, were used in the research. The measurement error for this type of thermocouples, within the temperature range from -20 to $+200{ }^{\circ} \mathrm{C}$, is $\pm 1.5^{\circ} \mathrm{C}$.

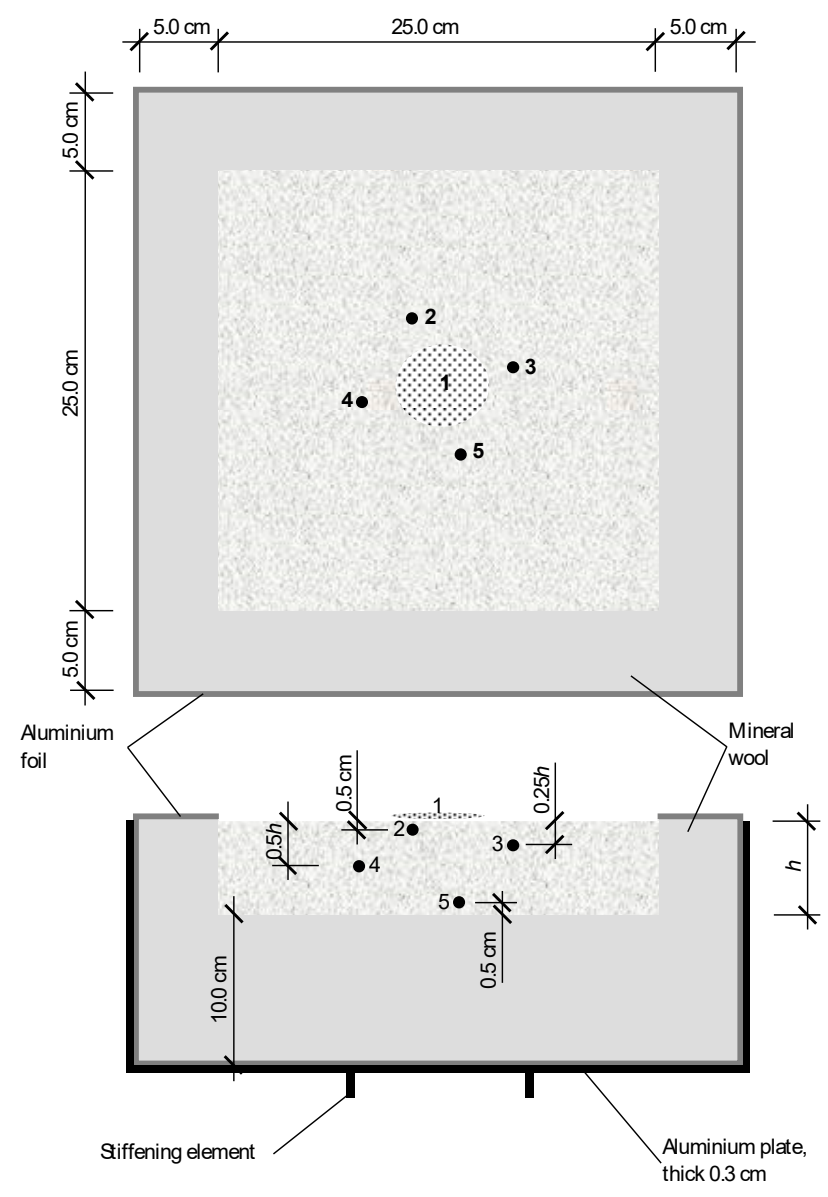

Figure 8. Schematic of HMA specimen prepared for temperature drop testing showing measurement locations.

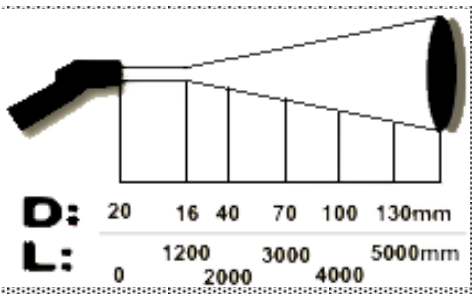

Figure 9. The size of the measured area for the used pyrometer using standard optics: D—diameter of measured area, L-distance from the object.

The tests were carried out at four ambient air temperatures $\left(0,5,15\right.$ and $\left.25^{\circ} \mathrm{C}\right)$ at $80 \% \pm 5 \% \mathrm{RH}$. The HMA specimens were heated up in a controlled manner in a drying oven to the initial temperature of $150{ }^{\circ} \mathrm{C}$ (measured at the specimen bottom-thermocouple No. 5). Spraying of the surfaces with water (cooled down to ambient temperature) was done by hand at $30 \mathrm{~s}$ intervals. The total amount of water used in the test was $200 \mathrm{~mL}$, corresponding to the water film of ca. $3.2 \mathrm{~mm}$ in thickness. The test duration was $1 \mathrm{~h}$. The thermal insulation (mineral wool) was additionally protected from the possible migration of water during wetting of the surface. This protection was made with the PTFE sheeting resistant to high temperatures (up to $260^{\circ} \mathrm{C}$ ).

The flow type was established on the basis of the product of Grashof and Prandtl numbers. The values of Gr and Pr were determined for the properties of water (specific heat, viscosity, density 
and thermal expansion) at the average temperature $\left(T_{m}\right)$ calculated with equation (10). With all the results for all the cases under analysis falling in the range of $\mathrm{Gr} \cdot \operatorname{Pr}>2 \cdot 10^{7}$ we deal with a turbulent flow of heat. An example of the Gr$\cdot \operatorname{Pr}$ calculation for water temperature of $0{ }^{\circ} \mathrm{C}$ and initial temperature of the HMA surface $\left(150^{\circ} \mathrm{C}\right)$ is shown in Table 3.

Table 3. Examples of Grashof and Prandtl (Gr·Pr) calculation.

\begin{tabular}{cccccc}
\hline Parameter & Value & Parameter & Value & Parameter & Value \\
\hline$T_{m}[\mathrm{~K}]$ & 384.15 & $c_{p}[\mathrm{~J} /(\mathrm{kg} \cdot \mathrm{K})]$ & $4.0680 \cdot 10^{3}$ & $\eta_{p}\left[\mathrm{~N} \cdot \mathrm{s} / \mathrm{m}^{2}\right]$ & $3.6861 \cdot 10^{-4}$ \\
$\lambda_{p}[\mathrm{~W} /(\mathrm{m} \cdot \mathrm{K})]$ & 0.66653 & $g\left[\mathrm{~m} / \mathrm{s}^{2}\right]$ & 9.81 & $\beta[1 / \mathrm{K}]$ & $2.8723 \cdot 10^{-3}$ \\
$\Delta T[\mathrm{~K}]$ & 75 & $d[\mathrm{~m}]$ & 0.25 & $\gamma_{p}\left[\mathrm{~kg} / \mathrm{m}^{3}\right]$ & $9.7436 \cdot 10^{2}$ \\
$\operatorname{Pr}$ & $2.2250 \cdot 10^{-3}$ & $\mathrm{Gr}$ & $9.5675 \cdot 10^{13}$ & $\mathrm{Gr} \cdot \mathrm{Pr}$ & $2.1524 \cdot 10^{11}$ \\
\hline
\end{tabular}

During the test it was noticed that there is no permanent water film on the surface of the HMA layer. Therefore, the heat is absorbed partially by water and partially by air. The heat transfer to the air corresponded to a significantly lower decrease in the values of the heat transfer coefficient $\alpha$. Further calculations were performed for a laminar flow (for water), which causes a less effective heat transfer (Table 1), approximate to induced flow of air.

The calculations of the temperature changes in the HMA surface cooled down with the water were performed using formula (1). The values of the heat transfer coefficient $\alpha$ were determined based on the A parameter (Table 1, laminar flow). The method of determining the A parameter is shown in Figure 10 (for average water temperature of $T_{m}=75^{\circ} \mathrm{C}$ ).

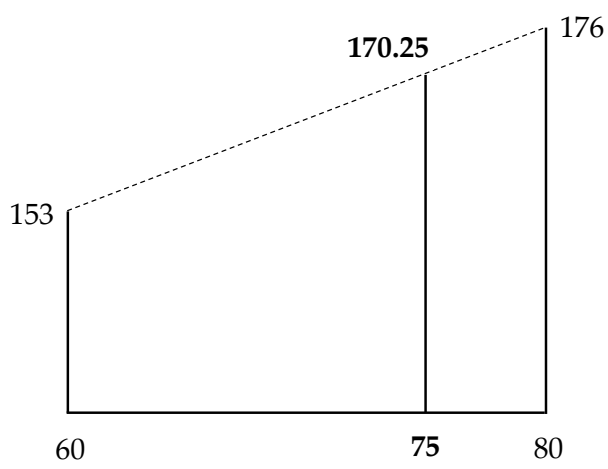

Figure 10. Method of determining the value of the A parameter based on Table 1.

The temperature drops inside the HMA layers obtained on the first three specimens (AC $16 \mathrm{~W}$, AC 8 S, SMA 11) were compared with their theoretical counterparts calculated for different values of $A$. Figure 11 presents examples of actual and theoretical (for $A=170.25$ ) temperature curves inside the AC $16 \mathrm{~W}$ specimen.

Analyzing the theoretical and measured temperature curves of two regions of varying fit were identified. The decisive factor was the duration of action and the depth in the vertical profile of the layer. The high amounts of heat transferred in the first time span ( $0-5 \mathrm{~min}$.) caused instantaneous drops of temperature mainly in the near-surface zone of the layer. This heat was used for phase transitions of water (boiling, evaporation). After that time, the process continued at a steady rate for some time to significantly slow down in the end. The temperature drops tend to equalize with increasing depth from the surface over the total test time. Intensification of the process in the first time span was not observed which is related to the slow flow of heat in the HMA layer (which depends on the value of $\lambda$ ). The average deviation between the measured and theoretical temperatures for tested samples (at all temperatures) was:

- Time range $0-5 \mathrm{~min} . \quad-14.2^{\circ} \mathrm{C}$,

- Time range $5-60 \mathrm{~min} . \quad-20.7^{\circ} \mathrm{C}$, 
- $\quad$ Total range $0-60 \mathrm{~min} . \quad-17.2^{\circ} \mathrm{C}$.

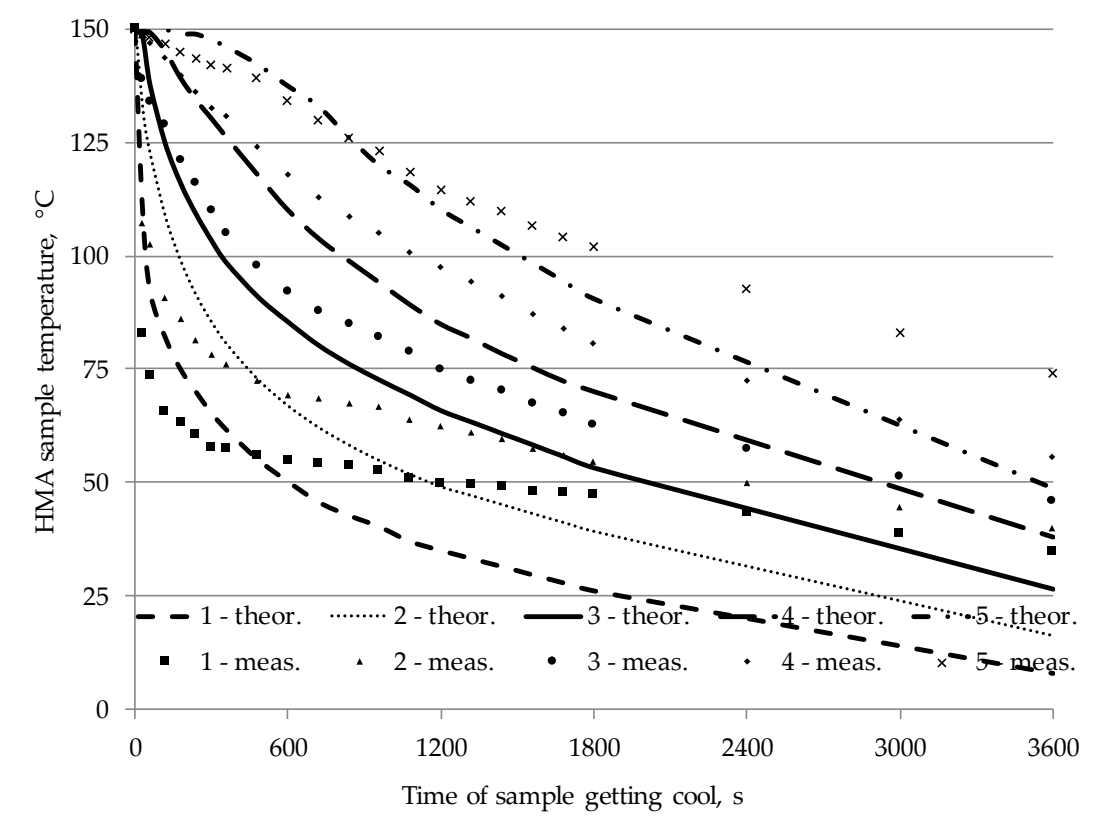

Figure 11. Drops of temperature in the AC $16 \mathrm{~W}$ specimen over time at ambient air temperature of $0{ }^{\circ} \mathrm{C}$. Legend: $1,2,3,4,5-$ measurement points according to Figure 8, theor--theoretical temperature obtained from the model, meas.- - measured temperature.

Significant differences between the experimentally measured and theoretical temperature were visible not only at the contact zone between HMA and water (1st measuring point) but also in all other points located in the cross-section of the HMA layer. This means that the theoretical model does not correspond to actual conditions. The main factor influencing such high discrepancies was the value of the heat transfer coefficient $\alpha$, which was determined based on the A parameter (Table 1). Proper revision of the coefficient value was conducted. Using the iteration for each measuring point, the least average deviations between the measured and theoretical temperatures were determined. At first the iteration was conducted for two time ranges $0-5$ and 5-60 $\mathrm{min}$. Later the time range was extended to 0-60 min. The results of the iteration process are visible in Figures 12 and 13.

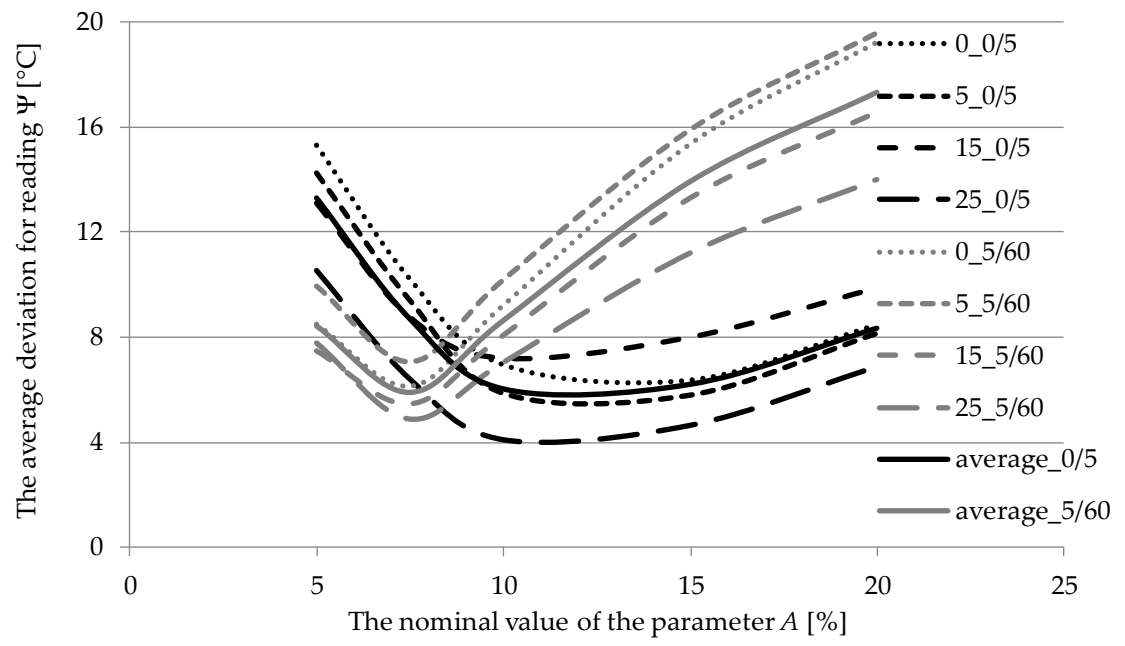

Figure 12. The mean absolute deviation $\Psi$ between the measured and theoretical temperatures for HMA specimens depending on the value of $\mathrm{A}$ and the ambient air temperature for $0-5 \mathrm{~min}$. and 5-60 min. time spans. 


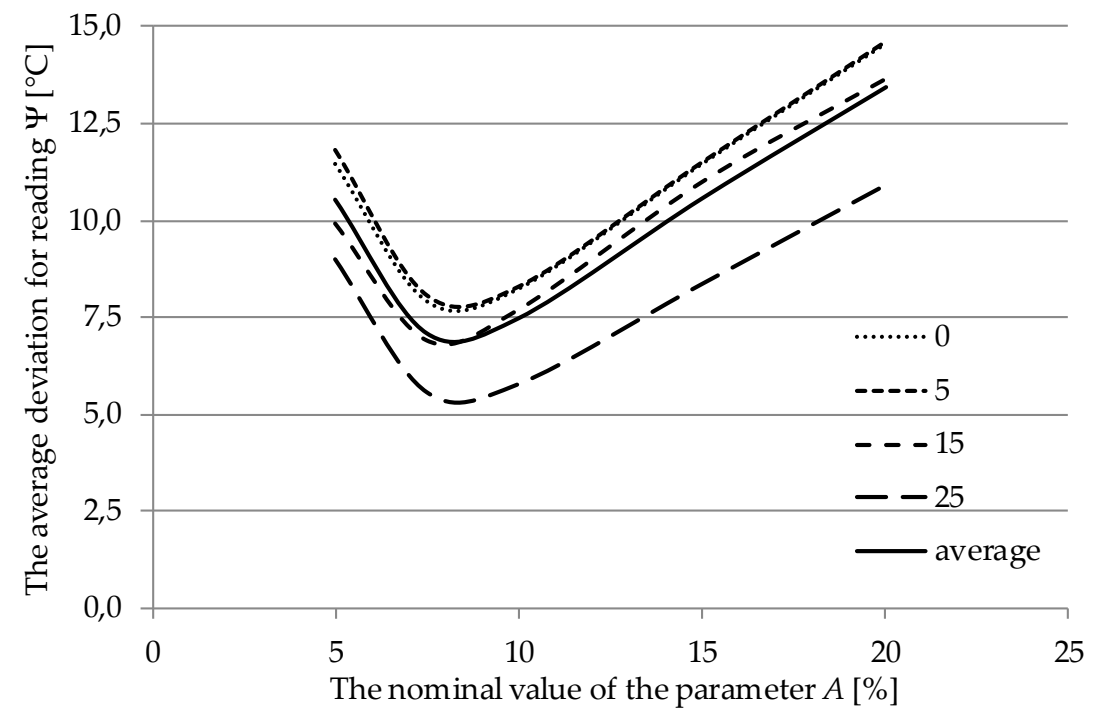

Figure 13. The mean absolute deviation $\Psi$ between the measured and theoretical temperatures for HMA specimens depending on the value of $A$ and ambient air temperature for the total test time.

The greatest convergence was obtained for $11 \%$ of the nominal value of $A$ in the first time span ( $0-5 \mathrm{~min}$.) and for $7.5 \%$ of that value in the second time span (5-60 min.). Based on the analysis performed for the total test time the optimum value of $A$ at the assumed amount of water should be ca. $8 \%$. The average deviation between the measured and theoretical temperature for the assumed $A$ parameter values in three studied samples cooled down with $3 \mathrm{~L} / \mathrm{m}^{2} / \mathrm{h}$ of water are shown in Table 4 .

Table 4. Value of average deviation $\Psi$ between measured and theoretical temperature for the assumed A parameter and $3 \mathrm{~L} / \mathrm{m}^{2} / \mathrm{h}$ of water.

\begin{tabular}{cccc}
\hline \multirow{2}{*}{$\begin{array}{c}\text { Value of A Parameter } \\
\text { (Table 1) [\%] }\end{array}$} & \multicolumn{3}{c}{$\begin{array}{c}\text { Value of Average Deviation } \Psi \text { between Measured and } \\
\text { Theoretical Temperature for Specific Time Range }\left[{ }^{\circ} \mathbf{C}\right]\end{array}$} \\
\cline { 2 - 4 } & $\mathbf{0 - 5}$ [min] & $\mathbf{5 - 6 0 ~ [ m i n ]}$ & $\mathbf{0 - 6 0 ~ [ m i n ] ~}$ \\
\hline 100 & 14.2 & 20.7 & 17.2 \\
11 & 6.0 & 8.6 & 7.6 \\
7.5 & 8.7 & 5.9 & 7.1 \\
8 & 7.7 & 6.2 & 6.8 \\
\hline
\end{tabular}

The assumptions concerning the value of $A$ were verified by comparing the sum of differences between the theoretical and measured temperatures, based on the experimental results obtained from testing the remaining four specimens (AC $22 \mathrm{P}, \mathrm{AC} 11 \mathrm{~W}, \mathrm{AC} 11 \mathrm{~S}$, SMA 8). The values of $\Psi(A)$ for the respective specimens were in the range of $6.3-7.7^{\circ} \mathrm{C}$, consistent with the range obtained in the quantification of this parameter for the first three specimens (Figures 12 and 13). Figure 14 presents the example experimental determinations of heat loss due to the action of water, through free convection and through radiation for the value of $A$ of $8 \%$ (nominal values from Table 1), the average for the total test time, for a chosen specimen of asphalt concrete for wearing course designated AC $11 \mathrm{~S}$.

The extremely well correlation of the theoretical model and measured conditions is visible already at $1 \mathrm{~cm}$ from the HMA surface. Near (up to $5 \mathrm{~mm}$ ) and at the surface of the layer the differences are noticeable. This is a result of the extensive outward heat transfer from the surface at the beginning of the cooling down due to boiling and evaporation processes. The reduction of the deviation between the theoretical and measured temperature was noticed with the increase of the initial temperatures of water and air. At $25^{\circ} \mathrm{C}$ the deviations were $1.5^{\circ} \mathrm{C}$ lower than at $0{ }^{\circ} \mathrm{C}$. This results from the lower heat demand (necessary for heating water) transferred from the surface of the HMA, thus the lower temperature drops in the initial stage of cooling down. 

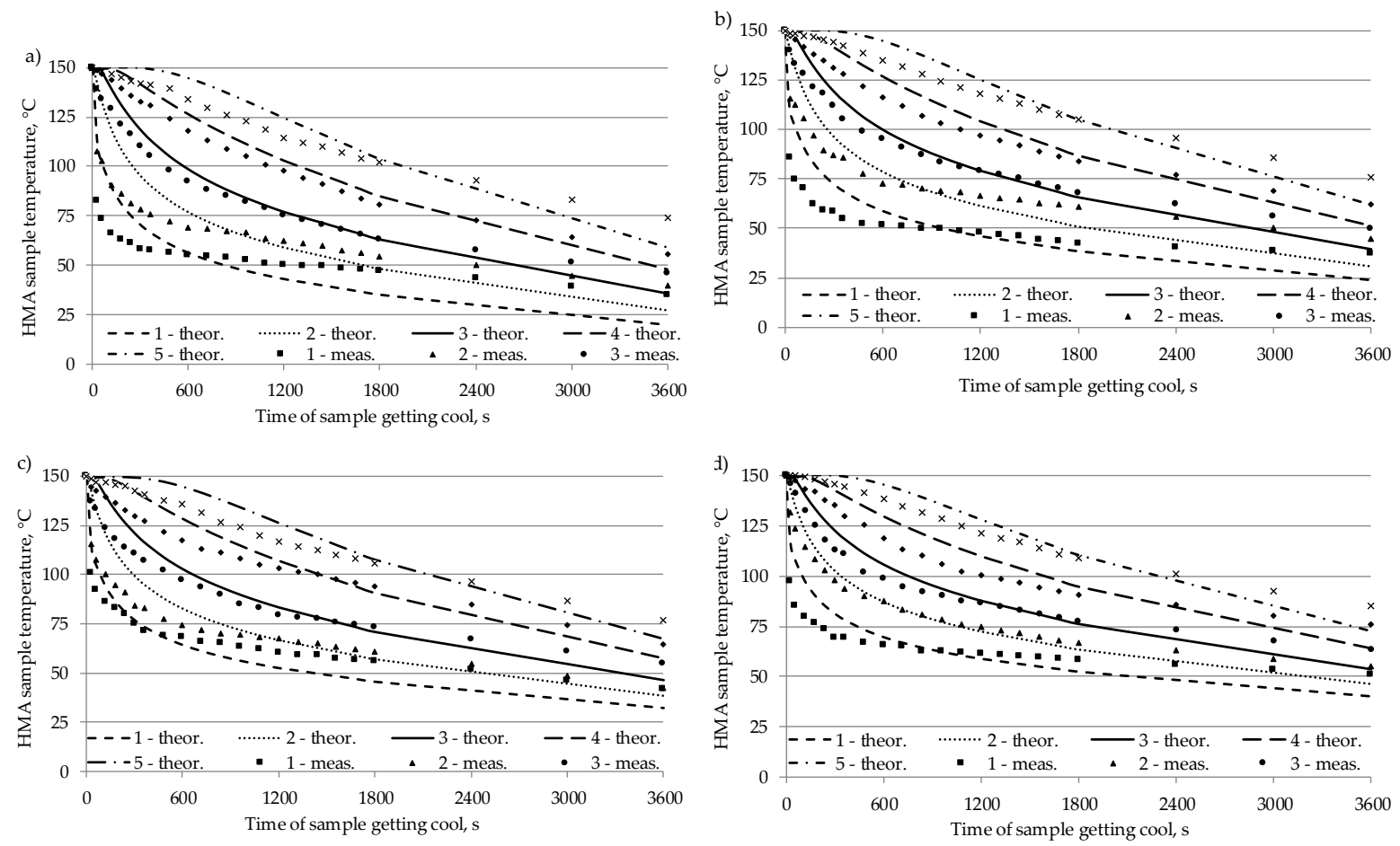

Figure 14. Drops of temperature in $\mathrm{AC} 11 \mathrm{~S}$ specimen over time for different ambient air temperatures: (a) $0{ }^{\circ} \mathrm{C}$, (b) $5{ }^{\circ} \mathrm{C}$, (c) $15^{\circ} \mathrm{C}$, (d) $25^{\circ} \mathrm{C}$. Legend: 1, 2, 3, 4, 5-measurement points according to Figure 8 , theor.-theoretical temperature obtained from the model, meas.-measured temperature.

The heat loss testing was continued with increased amounts of water applied on selected specimens ( $400 \mathrm{~mL}$ water was sprayed i.e., twice as much as previously). Initially all the water sprayed on the surface evaporated without forming a fluid film. The process slowed down over time and finally ca. $1 \mathrm{~mm}$ thick film has formed on the specimen surface. This behavior is an evidence of the complexity of the cooling process reflecting the physical transformations of water. The first minutes show that the HMA heat is used to turn water to vapor (with participation of boiling). Next, as the surface temperature decreases, a thin film of water starts to develop. This is related to the slowed down vaporization process due to a smaller amount of energy propagated from the "inside" of the specimen. As a result conduction comes into play as a new factor in the process of heat removal from HMA (following equalization of the layer surface and water temperatures). The HMA cooling rate slows down in this way due to the transfer of heat through the water film.

Same as previously, the tests (at application rate of $3 \mathrm{~L} / \mathrm{m}^{2} / \mathrm{h}$ ) were carried out on three specimens and the remaining four were used to verify the assumed values of $A$. The average deviation between the measured and theoretical temperature for the assumed $A$ parameter values in three studied samples cooled down with $6 \mathrm{~L} / \mathrm{m}^{2} / \mathrm{h}$ of water are shown in Table 5 .

Table 5. Value of average deviation $\Psi$ between the measured and theoretical temperature for the assumed A parameter and $6 \mathrm{~L} / \mathrm{m}^{2} / \mathrm{h}$ of water.

\begin{tabular}{cccc}
\hline \multirow{2}{*}{$\begin{array}{c}\text { Value of A Parameter } \\
\text { (Table 1) [\%] }\end{array}$} & \multicolumn{3}{c}{$\begin{array}{c}\text { Value of Average Deviation } \mathbf{\Psi} \text { between Measured and } \\
\left.\text { Theoretical Temperature for Specific Time Range [ }{ }^{\circ} \mathbf{C}\right]\end{array}$} \\
\cline { 2 - 4 } & $\mathbf{0 - 5}$ [min] & $\mathbf{5 - 6 0 ~ [ m i n ]}$ & $\mathbf{0 - 6 0 ~ [ m i n ] ~}$ \\
\hline 100 & 12.8 & 19.4 & 16.1 \\
13.5 & 5.6 & 8.2 & 7.1 \\
9 & 8.1 & 5.5 & 6.6 \\
11 & 7.2 & 6.0 & 6.4 \\
\hline
\end{tabular}


Based on the tests, the values of $A$ were determined depending on precipitation (amount of water), temperature of medium $\left(T_{m}\right)$ and the time of action (corrected in relation to the values presented in Table 1). This enabled the determination of the heat transfer coefficient $\alpha$, taking into account the characteristic length of the heat source (width of side $d$ ). The values of $\alpha$, derived from the formula (6) (for laminar flow), calculated as the average for total test time (i.e., $0-60 \mathrm{~min}$.) are presented in Figures 15 and 16 for different levels of precipitation: 3 and $6 \mathrm{~L} / \mathrm{m}^{2} / \mathrm{h}$. The average difference between the measured and theoretical temperatures of $6.6^{\circ} \mathrm{C}$ was obtained for all the tested specimens and measurement locations (using the values of $\alpha$ given in Figures 15 and 16). The acquired results exhibit a precision suitable for engineering purposes. The results allow to adjust the HMA application for difficult real life conditions and to predict the time necessary for proper compaction of the HMA.

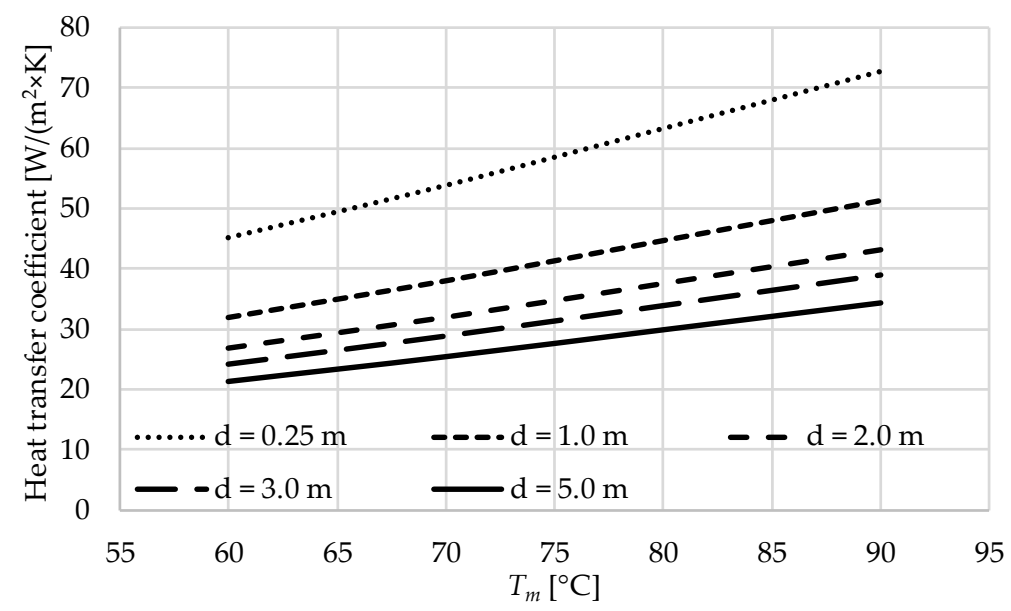

Figure 15. Values of the heat transfer coefficient $\alpha$ depending on the characteristic dimension of the layer (width-d) and precipitation rate of $3 \mathrm{~L} / \mathrm{m}^{2} / \mathrm{h}$

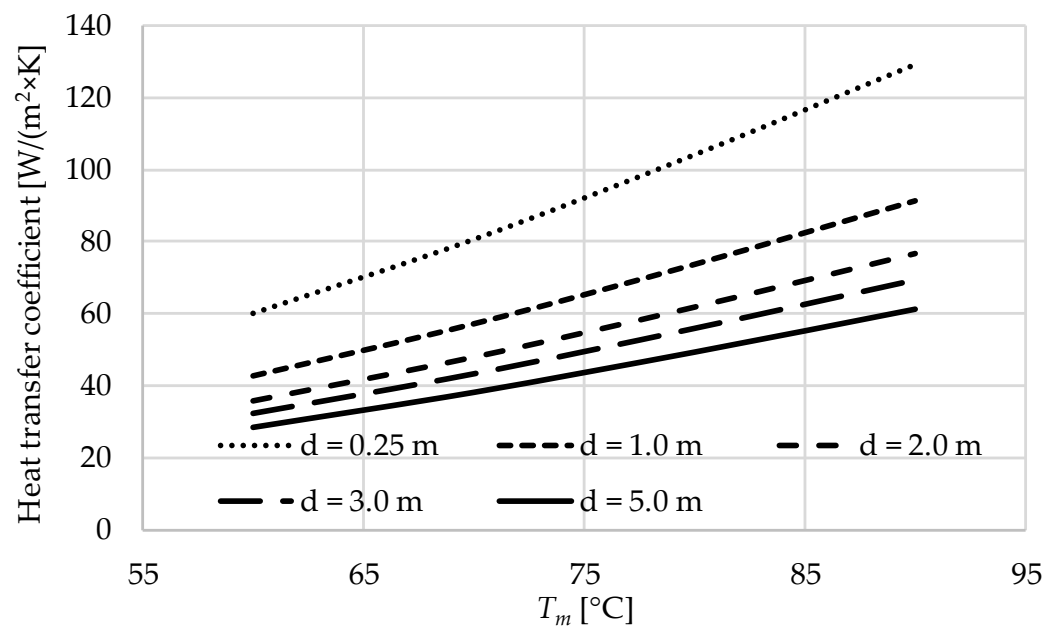

Figure 16. Values of heat transfer coefficient $\alpha$ depending on the characteristic dimension of the layer (width-d) at precipitation rate of $6 \mathrm{~L} / \mathrm{m}^{2} / \mathrm{h}$.

The values of $\alpha$ given in Figs. 15-16 are calculated as the average for the total heat transfer period (i.e., 0-60 $\mathrm{min}$.). Splitting this period in two time spans (0-5 min. and 5-60 $\mathrm{min}$.) we obtain values of $\alpha$ allowing a better fit between the calculated and measured values (Table 6). However, this significantly complicates the calculations. The average deviations between the measured and theoretical temperatures that were calculated based on the assumed values of $\alpha$ coefficient for all tested samples, both water amounts $\left(3 \mathrm{i} 6 \mathrm{~L} / \mathrm{m}^{2} / \mathrm{h}\right.$ ) and whole time spectrum are visible in Table 6. 
Table 6. Average deviation $\Psi$ between the measured and theoretical temperatures in relations to the assumed time range for all analyzed samples.

\begin{tabular}{cc}
\hline Time Range $[\mathrm{min}]$ & Average Deviation $\psi\left[{ }^{\circ} \mathbf{C}\right]$ \\
\hline $0-5$ & 5.8 \\
$5-60$ & 5.6 \\
$0-60$ & 6.6 \\
\hline
\end{tabular}

\section{Final Conclusions}

The results prove that the adopted model and values of the heat transfer coefficient $\alpha$ (calculated on the basis of experimentally obtained values of $A$ ) enable determination, with a good accuracy, of the temperature drops in the HMA layer. The average deviation between the measured and theoretical temperature was $6.6^{\circ} \mathrm{C}$. The result allows engineers to adjust the HMA laying process to difficult weather conditions and predict the time for necessary compaction.

A constant value of $\alpha$ can be adopted for practical purposes (for the total time period) depending on the precipitation rate, temperature difference between HMA and the surrounding environment and the characteristic length $(d)$ which considerably simplifies the calculations.

Large drops of temperature in a very short time in the HMA layer due to contact with water occur mainly near the surface. The influence of water (boiling and evaporation) is clearly visible in the comparison between the model and real conditions-the highest average deviation between the measured and theoretical temperature were noticed at the very surface of the HMA layer. The difference decreases towards the inside of the layer. At $1 \mathrm{~cm}$ from the surface the cooling down process is slow, showing that the proposed model to a good degree reflects the changes in the temperature in the HMA layer.

Studies on the influence of water on the cooling down of the HMA layer allowed do determine the values of the heat transfer coefficient $\alpha$ correlating them with $T_{m}$ and characteristic dimension $d$. In the case of water amount of $3 \mathrm{~L} / \mathrm{m}^{2} / \mathrm{h}$ the $\alpha$ coefficient corresponds to a convectional transfer (induced flow) at wind velocity of 3 to $12 \mathrm{~m} / \mathrm{s}$ (Figure 5). Increase in the water amount up to $6 \mathrm{~L} / \mathrm{m}^{2} / \mathrm{h}$ results in the increase of the $\alpha$ coefficient value, which correlates to convectional transfer at the wind velocity of 4 to $24 \mathrm{~m} / \mathrm{s}$ (Figure 5).

The values of the heat transfer coefficient during cooling with water are influenced by the initial temperature of water and the HMA layer. The higher the average temperature $\left(T_{m}\right)$, the more intense the heat exchange to the environment is (Figures 15 and 16). As a result, the surface will exhibit a much higher rate of cooling down. The differences in the temperatures inside the HMA layer are significantly lower. This is caused by a low thermal conductivity coefficient of the HMA layer.

Rapid temperature drops at the surface of the HMA layer with a contact with water can be a cause of decreased interlayer bonding. Such phenomenon can take place in the case where the HMA layer will be laid on a wetted subfloor. Laying of the HMA on a subfloor with high water content should be avoided, and if necessary, the subfloor should be dried using local space heaters.

Moreover, rolling the surface as soon as the paver has laid it will additionally counteract the penetration of precipitation water into the HMA structure, thus reducing the cooling rate and depth.

Further research includes the preparation of real-size section of a road. The influence of water on cooling down of the HMA layer and its density will be evaluated for the different water content in the subfloor. The effectiveness of compaction as the influence of the number of road roller cycles on the compaction index will be studied

Author Contributions: P.M. conceived and designed the experiments; P.M. performed the experiments; P.M. and B.B. analyzed the data; P.M. and B.B. wrote the paper.

Funding: This research received no external funding.

Conflicts of Interest: The authors declare no conflict of interest. 


\section{References}

1. Saedi, H. Assessment of Compaction Temperatures on Hot Mix Asphalt (HMA) Properties. World Acad. Sci. Eng. Technol. 2012, 62, 197-201.

2. Kassem, E.; Scullion, T.; Masad, E.; Chowdhury, A. Comprehensive Evaluation of Compaction of Asphalt Pavements and a Practical Approach for Density Predictions. J. Transp. Res. Board 2012, 98-107. [CrossRef]

3. Kennedy, T.; Roberts, F.; McGennis, R. Effects of Compaction Temperature and Effort on the Engineering Properties of Asphalt Concrete Mixtures. In Placement and Compaction of Asphalt Mixtures; Wagner, F., Ed.; ASTM International: West Conshohocken, PA, USA, 1984; ISBN 978-0-8031-0223-1. [CrossRef]

4. Williams, S.G.; Pervis, A.; Bhupathiraju, L.S.; Porter, A. Methods for Evaluating Longitudinal Joint Quality in Asphalt Pavements. Transp. Rese. Record 2009, 2098, 113-123. [CrossRef]

5. Willoughby, K.A.; Mahoney, J.P.; Pierce, L.M.; Uhlmeyer, J.S.; Anderson, K.W.; Read, S.A.; Muench, S.T.; Thompson, T.R.; Moore, R. Construction-Related Asphalt Concrete Pavement Temperature Differentials and the Corresponding Density Differentials. Research Report. Research Project Agreement T9903, Task A3 2001; Washington State Transportation Center: Washington, DC, USA. Available online: www.wsdot.wa.gov/ research/reports/fullreports/476.1.pdf (accessed on 10 March 2019).

6. Zhou, C.; Liu, X.; Apostolidis, P.; Scarpas, A. (Tom); He, L. Induction heating-assisted compaction in porous asphalt pavements: A computational study. Appl. Sci. 2018, 8, 2308. [CrossRef]

7. Mieczkowski, P. The heat exchange in the Edge area-the problem of hot mix asphalt compaction. Baltic J. Road Bridge Eng. 2015, 10, 207-215. [CrossRef]

8. Mahoney, J.P.; Muench, S.T.; Pierce, L.M.; Read, S.A.; Jakob, H.; Moore, R. Construction-related temperature differentials in asphalt concrete pavement: identification and assessment. Transp. Res. Record 2000, 1712, 93-100. [CrossRef]

9. Ma, T.; Zhang, Y.; Wang, H.; Huang, X.; Zhao, Y. Influences by air voids on the low-temperature cracking property of dense-graded asphalt concrete based on micromechanical modeling. Adv. Mater. Sci. Eng. 2016, 2016, 1-10. [CrossRef]

10. Ma, H.; Wang, D.; Zhou, C.; Feng, D. Calibration on MEPDG Low Temperature Cracking Model and Recommendation on Asphalt Pavement Structures in Seasonal Frozen Region of China. Adv. Mater. Sci. Eng. 2015, 2015, 1-11. [CrossRef]

11. A Manual for Design of Hot Mix Asphalt with Commentary; National Research Council (U.S.); National Cooperative Highway Research Program; American Association of State Highway and Transportation Officials; United States (Eds.) Nchrp report; Transportation research board: Washington, DC, USA, 2011; ISBN 978-0-309-15564-9.

12. Hobler, T. Ruch ciepła i wymienniki [Movement of Heat and Heat Exchangers]; WNT: Warszawa, Poland, 1986; ISBN 83-204-0064-3.

13. Kuppan, T. Heat Exchanger Design Handbook; CRC Press: Boca Raton, FA, USA, 2000; ISBN 978-1-57524-060-2.

14. Shah, R.K.; Sekulic, D.P. Fundamentals of Heat Exchanger Design; Wiley, John \& Sons, Incorporated: Hoboken, NJ, USA, 2003; ISBN 978-0-471-32171-2.

15. Rohsenow, W.M.; Hartnett, J.P.; Cho, Y.I. Handbook of Heat Transfer, 3rd ed.; McGraw-Hill handbooks; McGraw-Hill: New York, NY, USA, 1998; ISBN 978-0-07-053555-8.

16. Von Böckh, P.; Wetzel, T. Heat Transfer: Basics and Practice; Springer: Heidelberg, Germany, 2012; ISBN 978-3-642-19182-4.

17. Mieczkowski, P. Modeling of Heat Exchange Process Between Hot Mix Asphalt and The Environment During Compaction; ZUT University Publishing House: Szczecin, Poland, 2014; ISBN 978-83-7663-171-4.

18. Kays, W.M.; London, A.L. Compact Heat Exchangers; Krieger Publishing Company: Malabar, FA, USA, 1988; ISBN 978-1-57524-060-2.

19. Wiśniewski, S. Wymiana Ciepta; PWN: Warszawa, Poland, 1988; ISBN 83-01-07917-7.

20. Mieczkowski, P. Exchange of heat in the process of HMA compaction. Baltic J. Road Bridge Eng. 2010, 5, 191-198. [CrossRef]

21. Incropera, F.P. Fundamentals of Heat and Mass Transfer, 6th ed.; John Wiley: Hoboken, NJ, USA, 2007; ISBN 978-0-471-45728-2.

22. Timm, D.H.; Voller, V.R.; Lee, E.; Harvey, J. Calcool: A multi-layer asphalt pavement cooling tool for temperature prediction during construction. Int. J. Pavement Eng. 2001, 2, 169-185. [CrossRef] 
23. Mieczkowski, P. The heat balance in the process of compacting of hot asphalt mineral mixture using steel rollers. Arch. Civil Eng. 2006, LII, 151-175.

24. Petela, R. Przeptyw ciepta. [Heat Flow]; PWN: Warszawa, Poland, 1983; ISBN 83-01-03065-8.

25. Staniszewski, S. Wymiana ciepła. Podstawy teoretyczne; PWN: Warszawa, Poland, 1979; ISBN 83-1-00243-3.

(C) 2019 by the authors. Licensee MDPI, Basel, Switzerland. This article is an open access article distributed under the terms and conditions of the Creative Commons Attribution (CC BY) license (http://creativecommons.org/licenses/by/4.0/). 